\title{
Micro Friction Stir Welding Process: State of the Art
}

\author{
Akshansh Mishra* \\ Department of Mechanical Engineering, SRM Institute of Science and Technology, Kattangulathur-603203 \\ Received 13 Jan 2018, Accepted 21 March 2018, Available online 24 March 2018, Vol.8, No.2 (March/April 2018)
}

\begin{abstract}
Micro friction stir welding ( $\mu F S W)$ process is mainly adapted from the Friction Stir Welding Process. This process is mainly used for joining dissimilar materials. Micro friction stir welding ( $\mu$ FSW) find its applications in thin walled structures, electrical, electronic and micro-mechanical assemblies. The significant challenges are faced when we downscale to achieve $\mu$ FSW. This paper addresses the current state of the understanding and development of Micro friction stir welding. This paper further outlines the results achieved after Micro friction stir processing of Aluminium alloys, Copper alloys and Zinc alloys.
\end{abstract}

Keywords: Micro friction stir welding; Aluminium alloys; FSW heat zones; Welding tool

\section{Introduction}

Friction Stir Welding process is a simple welding process which doesn't involve any fumes, red glowing material, spattering and a low noise process. Friction Stir Welding is a solid state joining process which works on thermo-mechanical principle. This process was invented by Wayne Thomas and his colleagues in TWI. In particular they developed friction extrusion, friction hydro-pillar processing and third party friction joining process (Lohwasser D, 2009). Micro Friction Stir Welding Process offers following advantages which find wide applications at micro scale level: a) Micro FSW increases the possibility of joining wide range of plasticisable materials (similar and dissimilar joints) which are used in micro assembly systems. b) Joints obtained are contamination free because there is no need of fluxes or any filler materials. c) Aluminium alloys which are difficult to weld at small scale can be easily welded without any use of shielding gas and d) this process results flaw free joints mainly products which require sealed packages.

$\mu F S W$ was carried out in the butt joint configuration of 5083 alloy with the thickness of $0.8 \mathrm{~mm}$ (Sattari S et al 2012). It was observed that microscopic defects easily formed at the nugget zone (NZ) under high welding speed, while sound joint could be obtained under temperature ranges from $430^{\circ} \mathrm{C}$ to $510{ }^{\circ} \mathrm{C}$.

Few materials which are involved in micro fabrications, such as polymers and soft alloys, can have very poor ability to be friction stir welded, especially at the micro-scale due to very high thermal conductivity and low softening with temperature and low coefficient of surface friction.

The problems which can be encountered in down scaling $\mu$ FSW applications are following:

a) It is difficult to produce complex probe geometries at small scales and therefore this technique is less useful in generating shear friction heating. b) more energy is required per unit weld volume as size decreases, and it is obtained by the shoulder friction. c) due to high rotational speed of the tool there is a risk of tearing with thin sheet parent materials and d) the surface area to volume ratio of the plastic zone increases with decreasing zone radius, so the surrounding parent material provides more rapid heat dissipation.

\section{Tool design for Micro friction stir welding}

Figure 1 shows the tool design criteria for Micro friction stir welding applications.
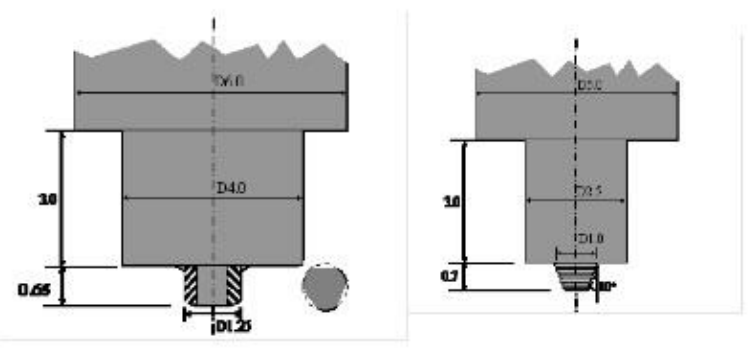

Figure 1: Tool design for Micro friction stir welding 
Proper tool design depends on the correct geometry of the shoulder and the pin. For example the radii used to minimise surface damage can be critical in micro applications where it is important to produce no flash.

\section{Micro friction stir welding of Aluminium alloys}

In the investigation conducted by Huang et al. it was observed that high joint quality of ultra -thin AA6061T4 sheets of thickness $0.5 \mathrm{~mm}$ was obtained (Huang, et $a l$ ). The tool used for Micro friction stir welding was made up of H13 tool steel having concave shoulder and taper pin or taper pin owning three flats as shown in the Figure 2. For successfully carrying out Micro friction stir welding process of $0.5 \mathrm{~mm}$ thickness sheets, the optimum plunging depth of $0.05 \mathrm{~mm}$ was selected.
This optimum plunging depth results the sufficient frictional heat, smaller flashes and thickness reduction as shown in Figure 3.

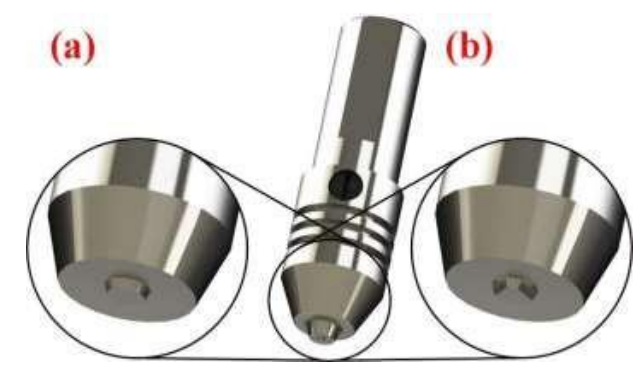

Figure 2: Schematic diagram of welding pins: a) the taper pin and (b) the taper pin with three flats

Table 1: Microstructures at different welding regions of the typical joints

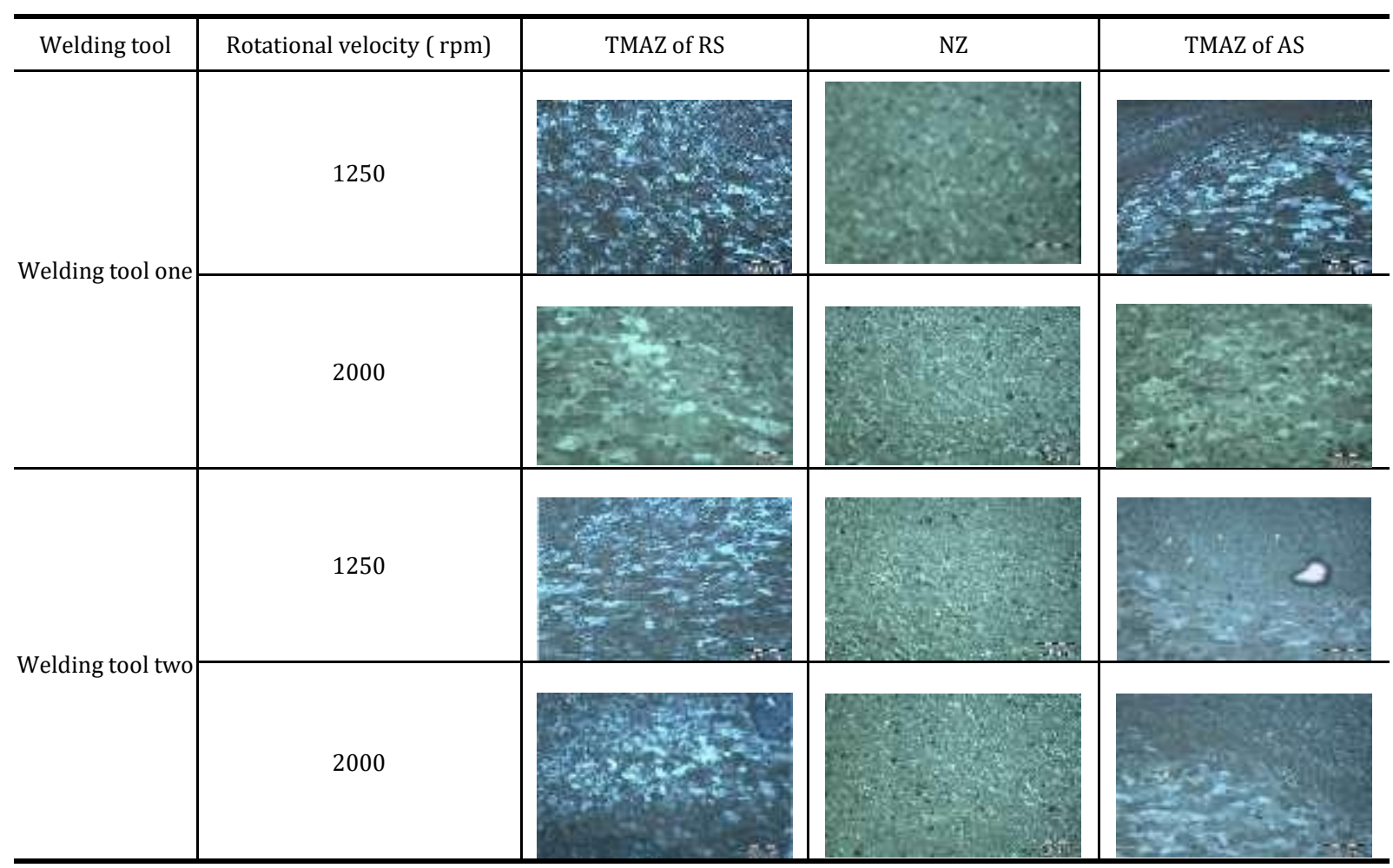
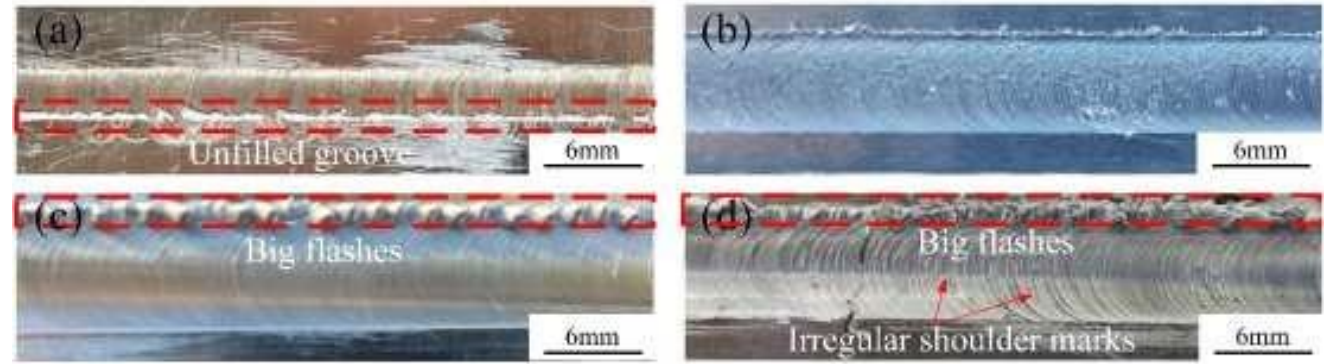

Figure 3: Effect of plunging depth on surface appearance of $\mu \mathrm{FSW}$ joint: (a) $0.02 \mathrm{~mm}$, (b) $0.05 \mathrm{~mm}$, (c) $0.08 \mathrm{~mm}$ and (d) $0.1 \mathrm{~mm}$

It was also observed that by increasing rotational velocity surface appearance was improved and kissing bond defect was eliminated. The Table 1 represents the microstructure obtained at different positions of Micro friction stir welded joints. Elongated grains were observed at BM due to rolling direction. Due to 
presence of thermal cycle and mechanical stirring, bended and deformed morphologies were obtained at TMAZ.

The main keypoint noted was that the interface between TMAZ and NZ at the AS indicates sharp morphology, while the interface between TMAZ and NZ at the retreating side (RS) exhibits unclear interface. This phenomenon is attributed to the differences of both shear stress and material flow on the two sides. The microstructure at the HAZ presents coarser morphology than BM. The HAZ only experiences the thermal cycle in absence of mechanical stirring phenomena.

Thus, it was concluded that at lower or higher plunging depth relative to $0.05 \mathrm{~mm}$, welding defects such as the unfilled groove, bigger flashes and thickness reduction were obtained.

\section{Micro friction stir welding of Copper alloys}

D. KLOBČAR et al. in his investigation successfully joined the copper electrical contacts by Micro friction stir welding process. He used a standard Cu ETP with temper R290 with its nominal chemical composition $\geq$ $99.9 \% \mathrm{Cu}$ and $0.005-0.04 \% \mathrm{O}$ (Klobčar, et al, 2014).

The appearance of surface weld after FSW with different parameters, tools and joint configurations is shown in Figure 4. Welds on Figure $4 \mathrm{a}$ and $4 \mathrm{c}$ were done with similar tool design (different pin length), the same welding parameters, and lap and butt joint configuration. The weld surface oxidized at the lap joint (Figure 4a) since higher temperature was generated due to smaller heat conduction.

It was also observed that the grain size in stir zone is reduced due to thermo-mechanical FSP which results good mechanical strength of the weld as shown in Figure 5.

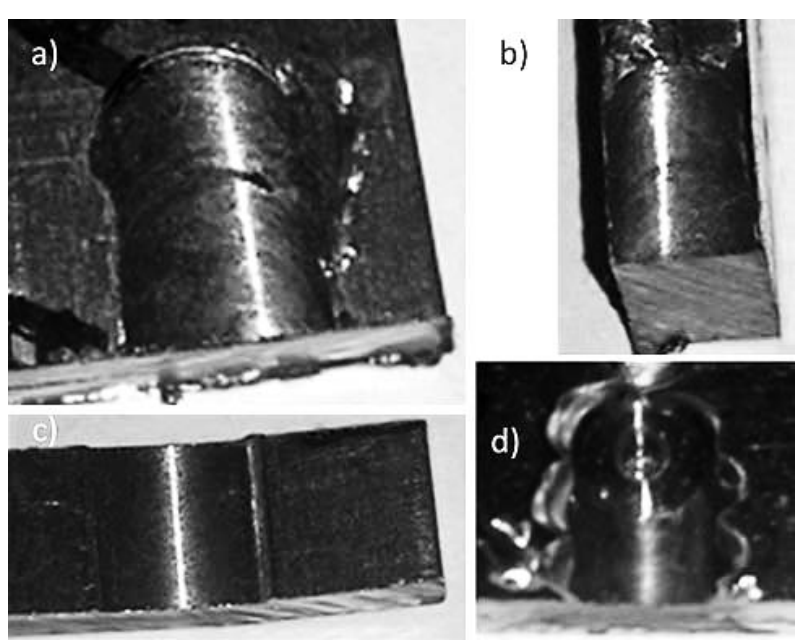

Figure 4: FSW weld surface appearance: a) lap joint (tool B, RPF = 20,4 rev $/ \mathrm{mm}, 93 \mathrm{~mm} / \mathrm{min}, 3^{\circ}$ ), b) butt joint (tool D, RPF = 135,7 rev $/ \mathrm{mm}, 14 \mathrm{~mm} / \mathrm{min}, 5^{\circ}$ ), c) butt joint (tool C, RPF = 20,4 rev $/ \mathrm{mm}, 93 \mathrm{~mm} / \mathrm{min}, 3^{\circ}$ ) and d) butt joint (tool D, RPF $=135,7 \mathrm{rev} / \mathrm{mm}, 14$ $\left.\mathrm{mm} / \mathrm{min}, 5^{\circ}\right)$

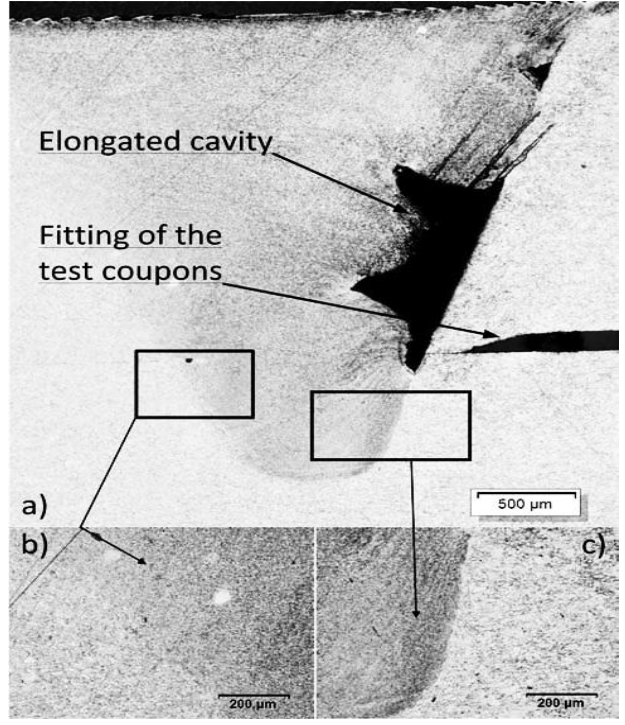

Figure 5: FSW weld microstructure (tool A, RPF = 10,1 $\mathrm{rev} / \mathrm{mm}, 116 \mathrm{~mm} / \mathrm{min}, 3^{\circ}$ ): a) the whole weld, and theinterface between stirred zone and base metal b) retreating side and c) advancing side of the tool.

\section{Micro friction stir welding of Zinc alloys}

Papaefthymiou et al. carried out Micro friction stir welding of wrought alloy of ZnTiCu sheets of $700 \mu \mathrm{m}$ thickness. The tool used for Micro friction stir welding was made up of X40CrMoV5-1 tool steel tempered at 500 degree $\mathrm{C}$, with the following dimensions: Shoulder diameter $5 \mathrm{~mm}$, Shoulder Height $5 \mathrm{~mm}$, pin diameter $0.5 \mathrm{~mm}$ and pin height $0.7 \mathrm{~mm}$. The tool was applied to the sheets under a 3 degree tilt angle (Papaefthymiou et al,2014).

The final geometry and dimensions of the welding tool as shown in Figure 6 was selected by the model with aim to minimize material loss and at the same time to have sufficient material displacement around the pin and under the shoulder.
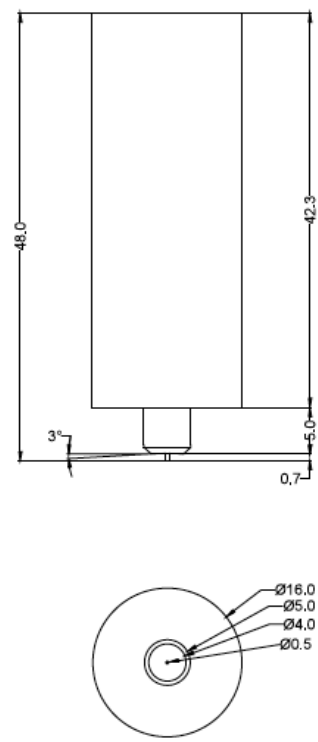

Figure 6: Geometry and dimensions of the used $\mu \mathrm{FSW}$ tool 


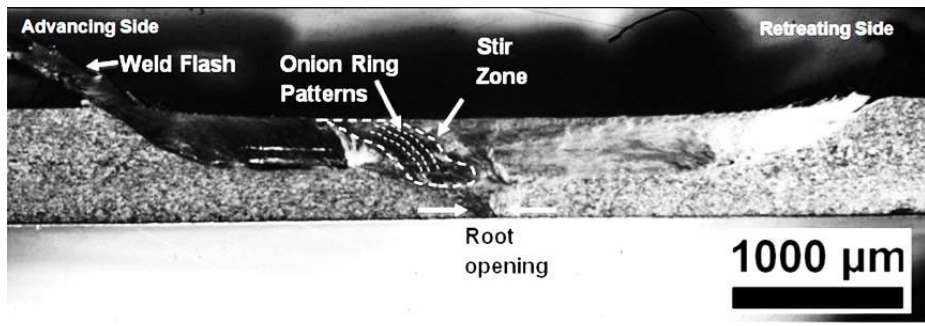

Figure 7: The characteristics of $\mu$ FSW (Stir Zone, onion rings, weld flash) are indicated. (FSW with $127 \mathrm{~mm} / \mathrm{min}$ at $1000 \mathrm{rpm})$.

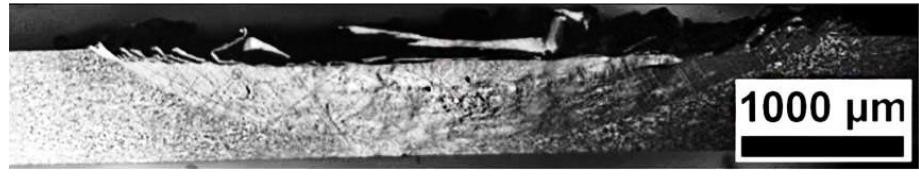

Figure 8: Weld flash formation

The microstructural evaluation shows that the highly elongated grains towards the rolling direction. The FSW regions i.e. Nugget, Stir Zone, Thermomechanically Affected Zone and onion ring patterns are identified in all joints, Figure 7 and Figure 8 . The presence of weld flash was also observed.

It was observed that the though Micro FSW joints were successfully completed, three main defects related to process parameters were observed: root opening, thinning and kissing bond.

\section{Results}

Micro friction stir welding can be carried out in Aluminium, Copper and Zinc alloys. It is also observed that the Micro FSW the metallurgical structure of the weld is fine grained and free of the segregation and coarse grains which can degrade fusion welds. Also in lap welds, defect free and weld structure with fine grained structure is produced.

\section{Conclusions}

We conclude that the very wide range of materials with dimensions less than $1000 \mu \mathrm{m}$ can be joined using this Micro friction stir welding technique including aluminium alloys, copper alloys and zinc alloys. This process requires accurate selection of tool design and geometries and proper material flow management.

\section{References}

Lohwasser D, Chen Z (Dec 2009), editors. Friction stir welding: From basics to applications. Elsevier;18.

Sattari S., Bisadi H., Sajed M. (2012), Mechanical Properties and Temperature distributions of Thin Friction Stir Welded Sheets of AA5083. Int. J. Mech. Appl., 2(1), 1-6.

Huang, Yongxian, Meng, Xiangchen, Zhang, Yabin, Cao, Jian, Feng, Jicai, Micro friction stir welding of ultra-thin Al-6061 sheets.Journal of Materials Processing Technology.

Klobčar, D., Tušek, J., Bizjak, M. and Lešer, V. (2014) Micro friction stir welding of copper electrical contacts. Metalurgija, 53(4), pp.509-512.

Papaefthymiou, S., Goulas, C., Gavalas, E.,Micro-Friction Stir Welding of Titan Zinc Sheets, Journal of Materials Processing Technology (2014), http:// dx.doi.org/10.1016/ j.jmatprotec.2014.08.029. 